\title{
Effectiveness of gold sea cucumber (Stichopus hermanii) extracts in accelerating the healing process of oral traumatic ulcer in rats
}

\author{
Dian Widya Damaiyanti ${ }^{*}$, Pratiwi Soesilowati², Ira Arundina ${ }^{2}$, Rima Parwati Sari ${ }^{1}$ \\ ${ }^{1}$ Department of Oral Biology, Faculty of Dentistry Hang Tuah University, Indonesia \\ 2Department of Oral Biology, Faculty of Dentistry Airlangga University, Indonesia
}

\begin{abstract}
Introduction: Gold sea cucumber (Stichopus hermanii) is a marine organism that contains omega-3 and glycosaminoglycan for enhancing collagen needed in the healing process. This study was aimed to determine the effectiveness of gold sea cucumber extracts in accelerating the healing process of oral traumatic ulcer in Wistar rats, in terms of the correlation between collagen type I expression, ulcer diameter, and body weight loss. Methods: Twenty Wistar rats (Rattus norvegicus) was divided into four groups and treated with gold sea cucumber extracts with the concentration of $80 \%, 40 \%$, and $20 \%$ in the form of $0.1 \mathrm{ml}$ gel daily. The negative control group received no treatment. Ulceration of the lower lip of labial mucosa was induced by a burnisher. The animals were observed for 7 days, during which they were weighed and the ulcers diameter was measured. The rats were then sacrificed after 7 days of treatment. Histometric analysis of collagen type I expression was also performed. Data obtained were analysed for differences between the group with one-way ANOVA test and the correlation was analysed with the Pearson test. Results: The significant differences $(p<0.05)$ between treatment groups was found in the ulcer diameters and the collagen type I expression. The most decreased ulcer diameter and the highest collagen type I expression detected in the group of treatment with a concentration of $80 \%-$ no significant differences found in the weight loss between-groups $(p>0.05)$. Strong correlation was also found between the expression of collagen type I and diameter of ulcer (Pearson correlation $=0.599, p=$ 0.05), however, no correlation found between weight loss with the expression of collagen type I (Pearson correlation $=-0.102, p=0.66$ ), and the ulcer diameter (Pearson correlation $=0.022, p=0.92$ ). Conclusion: Gold sea cucumber had a potential benefit to be used as a traumatic ulcer healing medicament. Water extract of gold sea cucumber able to accelerate traumatic ulcer healing by enhancing the production of collagen type I and reduce the diameter of ulcer. There is a strong correlation between collagen type 1 expression and diameter of ulcer, and a weak correlation found between body weight loss and collagen type I expression, also with reducing ulcer diameter.
\end{abstract}

Keywords: Gold sea cucumber, Stichopus hermanii, healing process, traumatic ulcer.

p-ISSN: 1979-0201; e-ISSN: 2549-6212; Available from: http://jurnal.unpad.ac.id/pjd/article/view/22555

DOI: 10.24198/pid.vol31no3.22555

Submission: Jul 15, 2019; Accepted: Nov 21, 2019; Published online: Nov 30, 2019

"Corresponding author: Dian Widya Damaiyanti, Department of Oral Biology, Faculty of Dentisry Hang Tuah University, Indonesia. Jalan Arief Rachman Hakim No. 150, Sukolilo, East Java, Indonesia, 60111. Phone: +628563385805; Email: damaiyanti@hangtuah.ac.id 


\section{INTRODUCTION}

Traumatic ulcers in the oral cavity are relatively frequent and are usually a result of mechanical injuries. Traumatic ulcers are typically found in non-keratinized surfaces such as the cheek mucosa, edge of the tongue, lips, gingiva, and also hard and soft palates. Lesions in the cheek and gingival mucosa can be caused by other forms of irritation such as brushing, which causes linear erosion along the free gingival margin and is sometimes related. They generally measure around $1 \mathrm{~cm}$ wide erythematous band and evolve to spontaneous healing in a period that can vary from 10 to 14 days, without leaving a scar. ${ }^{1}$ To overcome this injury, the healing process then present.

Wound healing is a specific biological process related to the general phenomenon of growth and tissue regeneration. It is characterised by the formation of a granulation tissue consisting of inflammatory cells, newly formed blood vessels and fibroblasts embedded in a loose collagenous extracellular matrix. Re-epithelization, angiogenesis and matrix deposition are critical events controlling this process. ${ }^{2}$ Wound healing constitutes a perfectly coordinated cascade of cellular and molecular events that interact to promote tissue repair. $^{3}$

Gold sea cucumber is a marine organism that has been known for at least several thousand years. Also known as echinoderms, or locally known as 'gamat', have a high content of eicosapentaenoic acid (EPA) which associated with the ability to initiate the tissue healing. ${ }^{5}$

Preliminary research of the similar subjects showed that the treatment using the water extract of gold sea cucumber increases the oral traumatic healing process by enhancing the wound closure that clinically can be seen in the decrease of ulcer diameter. ${ }^{6}$ Advance research performed in the present study was to examine the wound healing along with the collagen formation and the effect of ulcers on the weight loss of Wistar rat.

This study was aimed to determine the effectiveness of gold sea cucumber extracts in accelerating the healing process of oral traumatic ulcer in Wistar rats, in terms of the correlation between collagen type I expression, ulcer diameter, and body weight loss.

\section{METHODS}

This research was an experimental laboratory study with randomised post-test only control group design. Twenty Rattus norvegicus strain Wistar male, weighing 200-300 grams, aged 3 months, were provided by Biochemistry Department of the Faculty of Medicine Airlangga University.

\section{Animal}

The animals used had been approved by the Animal Care Committee of the Faculty of Dentistry Hang Tuah University, and performed by the guidelines of the Council on Animal Care of the Faculty of Dentistry Hang Tuah University. The rats were kept in the Animal Laboratory of the Faculty of Dentistry Hang Tuah University, given an initial examination for systemic health conditions and stored in boxes with sawdust. All animals were kept at the room temperature with controlled humidity.

\section{Extract of gold sea cucumber (Stichopus hermanii)}

Water extract of gold sea cucumber was made using the freeze-dried method. Concentration of the water extract of the gold sea cucumber gel were $80 \%$, $40 \%$, and $20 \%(\mathrm{~m} / \mathrm{v})$, made by diluting the water extract of gold sea cucumber powder in PEG 400:4000 base. Concentrations of 20\% was made by mixing 20 gram of powder mix with 100 $\mathrm{ml}$ PEG base. ${ }^{7}$

\section{Groups and treatment}

The animals were grouped into 4 groups of treatment: group 1 to 3 were given the water extract of gold sea cucumber gel with a concentration of $80 \%, 40 \%$, and $20 \%$ respectively. Group 4, as a negative control, was not given any treatment. Water extract of gold sea cucumber gel was applied into the ulcer on day 3 , when the ulcer first time can be observed once a day.

\section{Ulcer induction}

As preparation, the lower lip mucosa of the experimental animal was disinfected by using $0.12 \%$ chlorhexidine digluconate. The ulcer was made on this site with burnisher No. 4, diameter $2 \mathrm{~mm}$. The burnisher had been heated for 1 minute prior to application and then touched to Wistar rat's lip mucosa for 1 second to initiate 
ulcer. The ulcer was first seen on day 3 after given injury. Gold sea cucumber extract gel with a concentration of $80 \%, 40 \%$, and $20 \%$ then applied to the ulcer as much as $0.1 \mathrm{mg}$ for each treatment group, respectively (Figure 1).

\section{Clinical evaluation}

Ulcer diameter was measured with a digital calliper and the animals weighed with digital scales. All measurements were performed by the same operator. Ulcer diameter and body weight were evaluated on day 3 until day 7 .

\section{Immunohistochemistry assay}

The animals were sacrificed on day 7; then mucosa specimens were acquired. The specimen then proceed for hematoxylin and eosin (HE) staining and immunohistochemistry staining with monoclonal antibody anti-collagen type $1 .{ }^{8}$ Collagen type I expression was counted with modification of Brandacher methods. ${ }^{9}$ The histometric analysis was carried out using Olympus CX-22 and Optilab program, with 400x magnification. Sample slides were divided into 3 fields of view and scored using the proportion score multiplied with an intensity score technique. Proportion score $(1 \leq 25 \%), 2$ $(26 \%-50 \%), 3(51 \%-74 \%)$, and $4(\geq 75 \%)$, of the cells were detectable) and intensity score $(1=$ no staining/background of negative controls; 2 = weak staining detectable above background; 3 = moderate staining; $4=$ intense staining). ${ }^{9}$

\section{Statistical analysis}

Diameter of the ulcer was measured with a digital calliper on day 3 when the first ulcer can be observed, until day 7 when the average of rats were already healed. The diameter of ulcer, bodyweight loss, and collagen type I expression were analysed by ANOVA test. The relationship between the ulcer diameter, bodyweight loss, and the collagen type I expression variation from four experimental groups was analysed using Pearson correlation analysis.

\section{RESULTS}

\section{Diameter of ulcer}

Results of the present study was shown in Table 1 to Table 4, respectively. The most decreased ulcer diameter was found in Group 1 which applied

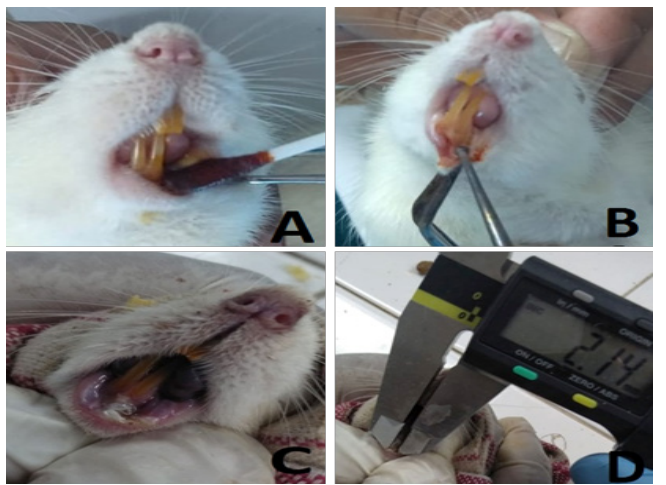

Figure 1. Ulcer induction in mucosa of experimental animal. A). Lower lip mucosa was smeared using $0.12 \%$ chlorhexidine digluconate; (B). Lower lip mucosa injured with a heated burnisher No. 4; (C). Traumatic ulcers Wistar rats appeared on day 3 after injured; (D) Ulcer was measured with digital calliper on day 3 until day 7

with water extract of gold sea cucumber in the concentration of $80 \%$, as presented in Table 1 .

ANOVA test result showed that there were significant differences $(p<0.05)$ in all groups. LSD analysis results (Table 2 ) showed that the differences between group 1 and 2, and between group 3 and 4 were not significant $(p>0.05)$, though the comparison in other group showed significant differences $(p<0.05)$.

Table 1. Diameter of ulcer

\begin{tabular}{ccc}
\hline \multicolumn{1}{c}{ Group } & $\Delta$ ulcer & SD \\
\hline 1 (Concentration 80\%) & 0.49 & 0.070 \\
$\mathbf{2}$ (Concentration 40\%) & 0.476 & 0.053 \\
3 (Concentration 20\%) & 0.352 & 0.051 \\
4 (Negative control) & 0.36 & 0.045 \\
\hline
\end{tabular}

Table 2. Post-hoc LSD test of diameter of ulcer

\begin{tabular}{llll} 
& $\begin{array}{c}\text { Group 2 } \\
(40 \%)\end{array}$ & $\begin{array}{c}\text { Group 3 } \\
(20 \%)\end{array}$ & $\begin{array}{c}\text { Group 4 } \\
\text { (negative } \\
\text { control) }\end{array}$ \\
\hline Group 1 (80\%) & 0.767 & $0.009^{*}$ & $0.013^{*}$ \\
Group 2 (40\%) & & $0.017^{*}$ & $0.024^{*}$ \\
Group 3 (20\%) & & & 0.866 \\
\hline *
\end{tabular}

*significant difference

Difference analysis using ANOVA test showed there were significant difference $(p<$ 0.05 ) in all groups. LSD test results (Table 2) showed insignificant differences in group 1 and 2 $(p>0.05)$, as also found between group 3 and 4 . However, the comparation in other group showed a significant difference $(p<0.05)$. 


\section{Body weight loss}

Ulcer characterised with loss of epithelium and exposure of connective tissue, that can cause pain and discomfort, and also weight loss. ${ }^{3}$

Table 3. Average body weight among groups

\begin{tabular}{lcc}
\hline \multicolumn{1}{c}{ Group } & $\begin{array}{c}\Delta \text { Weight (g) } \\
\text { (Day 7- Day 3) } \\
\text { (Mean) }\end{array}$ & SD \\
\hline $\mathbf{1}$ (Concentration 80\%) & -10 & 10 \\
$\mathbf{2}$ (Concentration 40\%) & 2 & 0.070569 \\
$\mathbf{3}$ (Concentration 20\%) & -3 & 10.36822 \\
$\mathbf{4}$ (Negative control) & 0.37 & 12.5499 \\
\hline
\end{tabular}

The present study results showed that the highest weight loss was found in group 1 , while in group 2 and 4 showed weight gain. Weight loss also found in group 3 (Table 3).

Table 4. Post-hoc LSD test of body weight loss

\begin{tabular}{cccc}
\hline Group & $\begin{array}{c}\text { Group 2 } \\
(40 \%)\end{array}$ & $\begin{array}{c}\text { Group 3 } \\
(20 \%)\end{array}$ & $\begin{array}{c}\text { Group 4 } \\
\text { (negative control) }\end{array}$ \\
\hline $1(80 \%)$ & 0.096 & 0.317 & 0.255 \\
$2(40 \%)$ & & 0.472 & 0.564 \\
$3(20 \%)$ & & & 0.885 \\
\hline
\end{tabular}

ANOVA test result showed that there were no significant differences among groups (Table 4), indicated that there were no differences in body weight loss among groups.

\section{The collagen type I expression}

Table 1 shows that the highest expression of collagen type I was found in group 1, which applied with water extract of gold sea cucumber with a concentration of $80 \%$ in a total of $5.86 \pm$ $0.91 \mathrm{mg}$. There was an increase in the expression of collagen type I in the group applied with $80 \%$, $40 \%$, and $20 \%$ of gold sea cucumber extract, consecutively, when compared with the negative control group.

Table 5. Average of the collagen type I expression

\begin{tabular}{lcc}
\hline \multicolumn{1}{c}{ Group } & Mean & SD \\
\hline 1 (Concentration 80\%) & 5.68 & 0.091 \\
2 (Concentration 40\%) & 4.13 & 0.377 \\
3 (Concentration 20\%) & 3.464 & 0.697 \\
4 (Negative control) & 3.2 & 0.122 \\
\hline
\end{tabular}

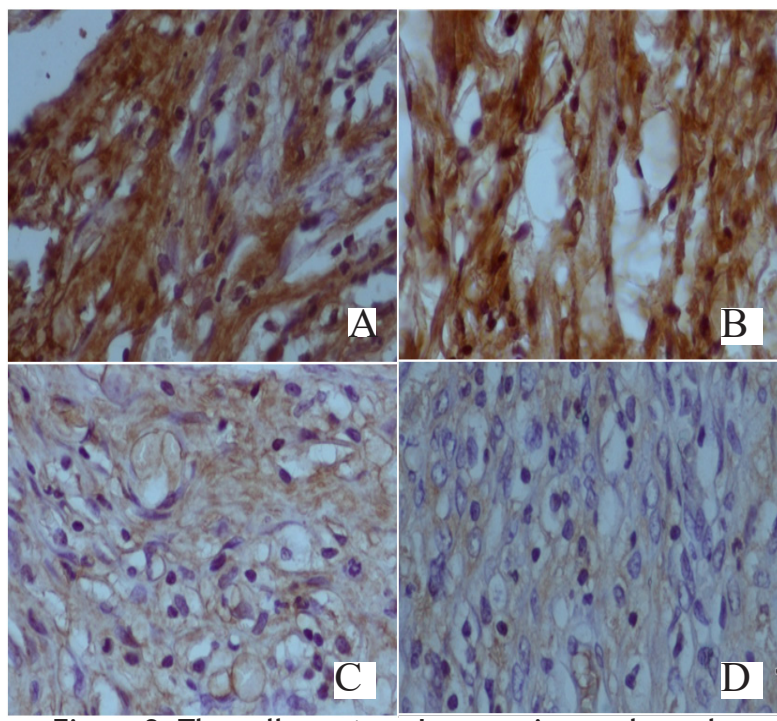

Figure 2. The collagen type I expression as shown by immunohistochemical staining using MoAb anti Collagen Type I. A). Collagen type I expression on group 1 (Concentration 80\%); B). Collagen type I expression on group 2 (Concentration 40\%); C). Collagen type I expression on group 3 (Concentration 20\%); D). Collagen type I expression on group 4 (Negative control)

The highest collagen type I expression was obtained in the group applied with gold sea cucumber extract with the concentration of $80 \%$. Post-hoc LSD analysis results showed significant differences among groups (Table 6).

There were significant differences obtained between group 1 (concentration of $80 \%$ ) and group 2 (concentration of $40 \%$ ), group $3(20 \%)$ and the negative control group $(p<0.05)$. And there was a difference between group 2 (concentration of $40 \%$ ) and group 3 (concentration of $20 \%$ ) and the negative control group $(\mathrm{p}<0.05)$.

Table 6. Post-hoc LSD test of collagen type I expression

\begin{tabular}{cccc} 
Group & $\begin{array}{c}\text { Group 2 } \\
(40 \%)\end{array}$ & $\begin{array}{c}\text { Group 3 } \\
(20 \%)\end{array}$ & $\begin{array}{c}\text { Group 4 } \\
\text { (negative control) }\end{array}$ \\
\hline $1(80 \%)$ & $0.001^{*}$ & $0.001^{*}$ & $0.0001^{*}$ \\
$2(40 \%)$ & & $0.029^{*}$ & $0.002^{*}$ \\
$3(20 \%)$ & & 0.207 \\
*significant difference & &
\end{tabular}

\section{Correlations among healing process indicator}

Significant correlations were found between the expression of collagen type I and diameter of ulcer (Pearson $r=0.599$ ), meanwhile, weak correlations were found between the expression of collagen type I and diameter of ulcer with body weight 
loss (Table 7). A negative correlation was found between the expression of collagen type I and body weight loss $(r=-102)$, the higher the collagen type I expression, the lower the body weight loss. The diameter of ulcer and body weight loss also had a weak correlation $(r=0.22)$ as all shown in Table 7 .

Table 7. Pearson correlation analysis between collagen type I expression, diameter of ulcer, and body weight loss

\begin{tabular}{|c|c|c|c|}
\hline & & $\begin{array}{l}\text { Ulcer } \\
\text { diameter }\end{array}$ & $\begin{array}{l}\text { Weight } \\
\text { loss }\end{array}$ \\
\hline \multirow{2}{*}{$\begin{array}{l}\text { Collagen type I } \\
\text { expression }\end{array}$} & $\begin{array}{l}\text { Pearson } \\
\text { correlation }\end{array}$ & $0.599^{* *}$ & -0.102 \\
\hline & & 0.005 & 0.669 \\
\hline \multirow{2}{*}{ Ulcer diameter } & $\begin{array}{l}\text { Pearson } \\
\text { correlation }\end{array}$ & & 0.022 \\
\hline & $\begin{array}{l}\text { Sig } \\
\text { (2-tailed) }\end{array}$ & & 0.928 \\
\hline
\end{tabular}

A negative correlation was found between the expression of collagen type I and body weight loss $(r=-102)$, the higher the collagen type I expression, the lower the body weight loss. The diameter of ulcer and body weight loss also had a weak correlation $(r=0.22)$ (Table 7).

\section{DISCUSSION}

Traumatic ulcer is the most common lesion in the oral cavity. It can be caused by poorly adapted prosthesis or occlusal disharmony, tooth crowns or fractured restorations, and even by accidental bites. There is no consent in the literature about a definite therapeutic protocol, and many times of inadequate treatments, such as the use of synthetic substances, phytotherapy and herbs are used by some of the population. ${ }^{1}$

Our study showed that the most decreasing diameter of the ulcer was found in group 1 (gold sea cucumber gel with a concentration of $80 \%$ ). The active compound in this group of treatment which was higher than other group had caused the area of the injury exposed at a constant rate until day 7 of the treatment. It is a well-accepted fact that wounds in most tissues heal by repair, by laying down non-specific connective tissue. Hence laying down and weaving of the collagen material into the healing wound is an important feature. Thus it is understandable that substances that influence the collagen turn over or maturation enhance the process of wound healing. Based on the literature suggested that existing glycosaminoglycan content in sea cucumbers may play a role as a modulator of inflammation such as macrophage, become more active. ${ }^{10}$

Glycosaminoglycans (GAGs) in gold sea cucumber, participate in a variety of biological processes including cell-matrix interactions and activation of chemokines, enzymes and growth factors. ${ }^{11}$ There are a variety of growth factors in the extracellular matrix (ECM), including members of the transforming growth factor-beta (TGF-B) superfamily, and vascular endothelial growth factor (VEGF). These growth factors stimulate cells and have been shown to improve wound healing. ${ }^{12}$ Proteoglycans are composed of several glycosaminoglycans that modulate the ability of heparin-binding growth factors, such as vascular endothelial growth factor (VEGF), and fibroblast growth factors (FGF). Proteoglycan regulates the activity of TGF- $B$ and the preparation of collagen fibrils in type I and III. The release of TGF-B led to an increase in collagen synthesis. ${ }^{10}$ The process of wound healing will occur faster, and clinically can be shown by the decrease of ulcer diameter.

The results of the present study showed that weight loss did not occur in all experimental groups; however, the treatment group applied with water extract of gold sea cucumber at the concentration of $80 \%$ and $20 \%$ showed weight loss, but in the group applied with water extract of gold sea cucumber at the concentration of $40 \%$ and negative control showed weight gain. Initial loss on the first day was caused by the process of ulcer induction in the mucosa, but at the end of day 7 , the results were varied. This data showed that the reduce of ulcer diameter not always improve life quality, other factors influence the rats' weight.

Omega 3 in sea cucumber extract also affects the production of prostaglandin $\mathrm{E}_{2}\left(\mathrm{PGE}_{2}\right)$ by increasing regulation of collagen production. 12 Omega-3 polyunsaturated fatty acids, of resolvins and protectins, which critically shorten the period of neutrophil infiltration by initiating apoptosis. The shorter the period of neutrophil leads to a shorter period of inflammation. The tissue damage due to inflammation can be avoided, and the next proliferation phase will run and wound healing can occur faster. ${ }^{14}$

Based on the statistic correlation of ulcer diameter, weight loss, and collagen type 1 expression. Ulcer diameter and collagen type 
1 expression have a strong correlation. This result proves that the expression of collagen type I will induce ulcer healing with clinical sign of decreasing ulcer diameter. ${ }^{15}$ Sulfated glycosaminoglycan (GAGs) from Stichopus hermanii, proved to accelerated wound healing trough wound contraction. ${ }^{2}$ The functions of proteoglycans (PGs)) and their associated GAGs, this molecules play a critical role in modulating the signalling media which is central to the patterning tissues, also described as morphogens, including Wnt, transforming growth factor/bone morphogenetic protein (TGF/BMP), and FGF. ${ }^{16}$ Meanwhile, the correlation between the ulcer diameter and collagen type I with weight showed a weak correlation, which indicates that ulcer diameter and collagen type I expression doesn't have any impact on body weight loss. This result may be due to the mucosa healing occurs faster. Gold sea cucumber (Stichopus hermanii), had a potential benefit to use as a traumatic ulcer healing medicament. Water extract of gold sea cucumber able to accelerate traumatic ulcer healing by enhancing the production of collagen type I and reduce the diameter of ulcer.

\section{CONCLUSION}

Gold sea cucumber (Stichopus hermanii), had a potential benefit to use as a traumatic ulcer healing medicament. Water extract of gold sea cucumber able to accelerate traumatic ulcer healing by enhancing the production of collagen type I and reduce the diameter of ulcer. There is a strong correlation between collagen type 1 expression and diameter of ulcer, and a weak correlation found between body weight loss and collagen type I expression, also with reducing ulcer diameter.

\section{REFERENCES}

1. Cavalcante GM, de Paula RJS, de Souza LP, Sousa FB, Mota MRL, Alves APNN. Experimental model of traumatic ulcer in the cheek mucosa of rats. Acta Cir Bras. 2011; 26(3): 227-34. DOI: 10.1590/S0102-86502011000300012

2. Masre SF, Yip GW, Sirajudeen KNS, Che Ghazali F. Wound Healing Activity of Total Sulfated Glycosaminoglycan (GAG) from Stichopus vastus and Stichopus hermanni integumental Tissue in Rats. Int J Mol Med Adv Sci. 2010; 6(4): 49-53. DOI: 10.3923/ijmmas.2010.49.53

3. Duarte CME, Quirino MRS, Patrocínio MC, Anbinder AL. Effects of Chamomilla recutita (L.) on oral wound healing in rats. Med Oral Patol Oral Cir Bucal. 2011; 16(6): e716-21. DOI: $10.4317 /$ medoral.17029

4. Taiyeb-Ali TB, Zainuddin SL, Swaminathan D, Yaacob H. Efficacy of "Gamadent" toothpaste on the healing of gingival tissues: a preliminary report. J Oral Sci. 2003; 45(3):153-9. DOI: 10.2334/josnusd.45.153

5. Aziz CBA, Wagiman MF, Hasan SK. The Analgesic Effects of Intraperitoneal Administration of Holothuria Extracts on Formalin-Induced Pain. Biomed Int. 2011; 2: 12-5.

6. Damaiyanti DW. Effect of water extract gold sea cucumber (Stichopus hermanii) on the ulcer diameter of oral traumatic healing process Wistar rats. In: Susilowati, Tanumihardja $M$, eds. Comprehensive Dentistry in The International Community. Proceedings of " ${ }^{\text {th }}$ International Dental Scientific Meeting"; 2014 June 20-22; Makassar, Indonesia. Makassar: Pustaka Refleksi; 2014.

7. Muryani E. Pengaruh Kombinasi Peg 400 Dan Peg 4000 Sebagai Basis Salep Terhadap Sifat Fisik Dan Kecepatan Pelepasan Benzokain [scientific report]. Surakarta: Muhammadiyah University of Surakarta; 2007.

8. Sudiana IK. Teknologi IImu Jaringan dan Imunohistokimia. Jakarta: Sagung Seto; 2004. p. 36-44.

9. Brandacher G, Perathoner A, Ladurner R, Schneeberger S, Obrist P, Winkler C, et al. Prognostic Value of Indoleamine 2,3-Dioxygenase Expression in Colorectal Cancer: Effect on Tumor-Infiltrating T Cells. Clin Cancer Res. 2006; 12(4): 1144-51. DOI: 10.1158/1078-0432.CCR-05-1966

10. Janakiram NB, Mohammed A, Bryant T, Lightfoot S, Collin PD, Steele VE, et al. Improved innate immune responses by Frondanol ${ }^{\circledR}$ A5, a sea cucumber extract, prevent intestinal tumorigenesis. Cancer Prev Res (Phila). 2015; 8(4): 327-37.

11. Taylor KR, Gallo RL. Glycosaminoglycans and their proteoglycans: host-associated molecular patterns for initiation and modulation of 
inflammation. FASEB J. 2006; 20(1): 9-22. DOI: 10.1096/fj.05-4682rev

12. Serra MB, Barroso WA, da Silva $N N$, do Nascimento Silva S, Borges ACR, Abreu IC, et al. From Inflammation to Current and Alternative Therapies Involved in Wound Healing. Int J Inflam. 2017; 2017: 3406215.

13. Watkins BA, Li Y, Lippman HE, Seifert MF. Omega-3 polyunsaturated fatty acids and skeletal health. Exp Biol Med (Maywood). 2001; 226(6): 485-97.
14. Serhan CN, Savill J. Resolution of inflammation: The beginning programs the end. Nat Immunol. 2005; 6(12): 1191-7. DOI: 10.1038/ni1276

15. van Beurden HE. Characterization of fibroblast phenotypes in intra-oral wound healing [thesis]. Nijmegen: Radboud University Nijmegen; 2006.

16. Princivalle $M$, de Agostini A. Developmental roles of heparan sulfate proteoglycans: a comparative review in Drosophila, mouse and human. Int J Dev Biol. 2002; 46(3): 267-78. 